\title{
ISLAM DAN KESEJAHTERAAN MASYARAKAT : SIASAT USAHA PEDAGANG KAKI LIMA DENGAN PEMANFAATAN HUBUNGAN KOMUNITAS MUSLIM
}

\author{
Mohammad Syawaludin \\ Syawalibrahim71@gmail.com \\ 081271677835
}

\begin{abstract}
The main subject of this research that is; Streer traders form a community and use it as a business tactics that make an important contribution to the value of their welfare. Including this section of research is to explain in depth the pattern of Muslim street traders community relationships and forms of community use as a business tactic. With the theory of parson structural functionalism in assisting with the social network theory of Luhkmanns and the value exchange theory of Homas, the framing of the relationship between the Muslim street traders community relationship with the value of benefit and welfare value is used to explain the activities of the social system and the daily activities of the street vendors. The results showed that the community of Muslim street vendors in the market Suak Bato Palembang as a form to respond challenging responses of uncertain market life both in terms of price stability and supply of merchandise. Relevance with the teachings of Islam shows a variety of practices and also related to the awareness of street vendors and the environment around him. Islamic narration practiced by Muslim street vendors among others; sincere behavior, keeping merchandise halal, barakah behavior, honest and fair and open behavior in scales.
\end{abstract}

Keywords : Street Traders; Community; Business Strategy; Cybernetics.

\begin{abstract}
Abstrak
Adapun yang menjadi pokok penelitan ini yakni; pedagang kali lima (PKL) membentuk komunitas dan memanfaatkannya sebagai siasat usaha yang memberi kontribusi penting bagi nilai kesejaterahaan mereka. Termasuk bagian penelitian ini ialah menjelaskan secara mendalam pola hubungan komunitas PKL muslim dan bentuk-bentuk pemanfaatan komunitas yang dijadikan siasat usaha. Dengan teori fungsionalisme struktural parson di bantu dengan teori jaringan sosial dari Luhkmann serta teori pertukaran nilai dari Homas maka pembingkai hubungan antara hubungan komunitas PKL Muslim dengan nilai kemanfaatan dan nilai kesejateraan digunakan untuk menjelaskan aktifitas dari sistem sosial.serta keseharian para PKL. Hasil penelitian menunjukan bahwa komunitas PKL muslim di pasar Suak Bato Palembang sebagai bentuk menjawab respons tantangan (challenger responses) kehidupan pasar yang tidak menentu baik dari sisi stabilitas harga maupun suplai bahan dagangan. Relevansinya dengan ajaran Islam menunjukan wujud praktik yang bervariasi dan terkait juga dengan kesadaran PKL serta lingkungan di sekelilingnya. Narasi Islam yang dipraktekan oleh para PKL muslim diantaranya; perilaku
\end{abstract}




\section{Mohammad Syawaludin}

ikhlas, menjaga dagangan tetap halal, perilaku barakah, perilaku jujur dan adil serta terbuka dalam timbangan.

Kata kunci : Pedagang kaki lima; komunitas; strategi bisnis;garis perilaku

\section{Pendahuluan}

Sektor informal merupakan urat nadi kehidupan ekonomi jutaan rakyat kecil, terutama di kota. Oleh karena itu sektor ini bukan saja sumber mata pencaharian yang menyangkut rakyat miskin tetapi juga menyediakan secara sangat luas lapangan kerja bagi mereka yang tidak memiliki pekerjaan formal. Dengan demikian, sektor ini merupakan denyut kehidupan ekonomi rakyat kecil yang mempunyai peranan yang sangat strategis dalam upaya meningkatkan pendapatan mereka. Golongan masyarakat margin yang salah-satu kelompok sektor ini adalah Pedagang Kaki Lima (PKL) .

Pedagang kaki lima (PKL) merupakan pelaku usaha informal yang juga masuk kategori miskin ataupun rentan. Banyak dari mereka menjadi PKL karena memang tidak punya pilihan lain. Kerentanan mereka antara lain menyangkut pada modal terbatas, kegiatan usaha subsisten, tidak adanya ijin usaha, dan ketiadaan jaminan tempat usaha, tidak memiliki keahlian khusus mengharuskan mereka bertahan dalam suatu kondisi yang memprihatinkan, ditambah dengan berbagai aturan seperti adanya Perda yang melarang keberadaan mereka. Keberadaan PKL kerap dianggap ilegal karena menempati ruang publik dan tidak sesuai dengan visi kota yang sebagian besar menekankan aspek kebersihan, keindahan dan kerapihan kota. 


\section{Islam dan Kesejahteraan Masyarakat : Siasat Usaha Pedagang Kaki Lima dengan Pemanfaatan Hubungan Komunitas Muslim}

Tidak semua yang diperbuat oleh PKL berdampak negative dan mendatangkan problem sosial. Usaha PKL untuk meningkatkan tarap kehidupan mereka adalah sesuatu yang berdampak positif. Profesi sebagai PKL telah terbukti sebagai jarring pengaman sosial yang mencegah mereka terjerumus lebih jauh dalam lembah kemiskinan. Sisi positif dari PKL di atas menggambarkan suatu kondisi bahwa mereka mampu dan menemukan siasat usaha untuk bertahan hidup dengan menciptakan jaring kesejateraan sendiri. Ini merupakan sesuatu yang menarik untuk diteliti secara holistik terutama dari proses menciptakan siasat usaha PKL yang memanfaatkan kultur sosial dan pandangan moral tertentu menjadi dasar bagi semangat komunitas mengentaskan kemiskinan. Adapun Pedagang Kaki Lima (PKL) yang akan diteliti adalah PKL Muslim di Pasar Suak Bato 26 Ilir Palembang.

\section{Metode Penelitian}

Seturut dengan paparan persoalan di atas, pertanyaan utama penelitian ini adalah; Mengapa pedagang kali lima (PKL) membentuk komunitas dan memanfaatkannya sebagai siasat usaha serta respon keadaan di sekitar mereka dan Bagaimana semangat keislaman yang ada di dalam siasat usaha PKL di Pasar Suak Bato Kota Palembang ? Adapun penelitian ini bertujuan di antaranya Menggambarkan secara utuh pola hubungan komunitas PKL Muslim di Pasar Suak Bato Palembang.dan Menjelaskan berbagai bentuk dan komunitas PKL muslim yang dijadikan siasat usaha mereka.selanjutnya menjelaskan semangat ajaran islam yang 


\section{Mohammad Syawaludin}

mempengaruhi atau member kontribusi terhadap perilaku perniagaan yang mendorong nilai-nilai kesejateraan PKL. Semantara manfaat penelitian ini adalah Secara akademik hasil penelitian ini akan menambah kepustakaan ilmu pengetahuan khususnya berbasis pengembangan keilmuan sosial dan islam.

Karena spesifikasi kajian ini adalah pengembangan keilmuan yang menggunakan pendekatan sosiologi dan agama. Secara teoritis diharapkan hasil kajian ini dapat dijadikan salah-satu contoh studi sosial yang menggunakan pendekatan keilmuan sosiologi secara mikro dan saling melengkapi. Yakni teori fungsionalisme structural, teori jaringan sosial dan teori pertukaran nilai. Kesemua teori tersebut berada dalam tradisi sosiologi durhemian.

Penelitian ini akan menggunakan teori sosial fungsionalisme Parsons ${ }^{1}$ dan Nicklas Luhmann², untuk melihat bagaimana siasat usaha PKL dibangun dan dijadikan dasar melakukan tindakan usaha dalam rangkah pengentasan kemiskianan. Selain itu untuk menggambarkan hubungan dan pola-pola komunitas sesama PKL yang terjadi sehari-hari. Teori ini juga akan melihat pengaruh dari nilai keyakinan dan norma yang menjadi kekuatan bertahan dan penciptaan jaring kesejateraan orang-orang yang lemah secara struktural dan politik ${ }^{3}$ Dalam perspektif fungsionalisme Parsons, relasi sosial dan kepentingan ekonomi dilandasi oleh

\footnotetext{
${ }^{1}$ Peter Hamilton, Reading From Talcott Parsons, Terjemahan oleh Hartono Hadikusumo, Tiara Wacana, 2000: 1. Lihat juga George Ritzer dan Douglas J. Goodman, Terjemahan oleh Alimandan, edisi ke 6, cet ketiga, Pranada Media, 2005, hlm: 121

2 Nicklas,Luhkmann Social Systems, California: Stanford University Press, 1995

3 Doddy S. Singgih, "Metode Analisis Fungsi Lahan,” Masyarakat Kebudayaan dan Politik, Th XII, No 3 , Juli 1999, 1-8. dan lihat juga artikelnya " Prosedur Analisis Stratifikasi Sosial dalam Perspektif Sosiologi”, Fisip Unair.
} 


\section{Islam dan Kesejahteraan Masyarakat : Siasat Usaha Pedagang Kaki Lima dengan Pemanfaatan Hubungan Komunitas Muslim}

pertimbangan moral kolektif. Setiap orang-orang yang lemah secara ekonomi pada dasarnya termotivasi menuntut keuntungan dari tindakan kolektif dengan partisipasi sekecil mungkin. Bila suatu kondisi bereaksi terhadap faktor-faktor yang menekan mereka, maka bukan karena " tradisi mereka " terancam oleh ekonomi pasar yang kapitalistik namun karena mereka ingin memperoleh kesempatan " hidup " dalam tatanan ekonomi baru ini. Apa yang disebut sebagai "etika subsistensi" (etika untuk bertahan hidup dalam kondisi minimal) melandasi segala perilaku kaum tertindas pada umumnya. ${ }^{4}$.

Dalam konteks ini, moralitas menjadi indikator untuk mengukur baik atau buruknya jalinan hubungan sosial. Sebab sistem dan fungsi masyarakat dianggap sebagai salah satu instrumen untuk menjalin hubungan sosial yang berlandaskan pada moralitas5 ${ }^{5}$ Di sini moral memainkan peran penting, motivasi-motivasi moral seseorang dianggap dibentuk oleh sistem keyakinan dan norma yang membudaya yang membimbing kekuatan mereka untuk bertindak. Bahkan menurut Schejtman yang mengatakan bahwa perilaku wirausahawan terlihat terutama pada sikap

\footnotetext{
${ }^{4}$ James C. Scott, Everydav Forms of Peasant Resistance New Haven: Yale University Press, 1984: 8.

${ }^{5}$ Moral Economy is an economic ethic that arises under conditions of struggle for subsistence. Grounded on an ethic of necessity, it insists, that, where the community's economic well being is concerned, market forces and the profits of individuals should be subdued to non market principles of distribution, Lihat Thompson, Customs in Common London: Merlin Press, 2012: 337. Lihat James C. Scott, popularized E.P. Thompson's idea with his well-known study of peasant revolts in Vietnam and Burma, The Moral Economy of the Peasant: Rebellion and Subsistence in Southeast Asia New Haven: Yale University Press, 1976.
} 


\section{Mohammad Syawaludin}

mereka menghadapi resiko.yakni dalam risk internalization ${ }^{6}$. Seorang wirausahwan memanfaatkan fungsi-fungsi dari segala kemungkinan dan itu tidak statis ${ }^{7}$.

Moralitas ekonomi mendahulukan keselamatan ini adalah suatu "episode sangat penting" untuk memahami kondisi suatu kelas sosial. Prinsip mendahulukan keselamatan merupakan sumber kekuatan moral bagi masyarakat yang mengalami kesulitan ekonomi untuk mengikuti perubahan yang tidak memberi pilihan lain. Dengan kata lain, sikap responsif mereka terwujud dalam bentuk kewirausahaan dan dalam rangka memperjuangkan kelangsungan subsistensi mereka sendiri. Parsons menilai, desa atau tempat-tempat marginal diperkotaan seperti yang dijumpai di negara-negara maju adalah lebih mendekati suatu unit ritual dan budaya yang memiliki rasa senasib dan sepenanggungan seperti pasar, terminal, pinggir jalan ${ }^{8}$. Bila dikaitkan dengan Pedagang Kaki Lima (PKL) yang mampu mengolah kesusahan hidupnya dengan cara bersiasat yakni kerjasama, membentuk komunitas dan membangun sistem sendiri dikalangan mereka. Kemudian menciptakan usaha sebagai cara untuk tetap hidup dan meningkatkan tarap kehidupan merupakan suatu

6 Schejtman. A. The peasant economy internal logic; articulation nd persintence dalam the political economy of underdevolepment, C.K.Wilber, ed, newyork Raundem House: 1984, hlm: 67-70.

${ }^{7}$ Schejtman. A. ibid, hlm: 283.

${ }^{8}$ Berdasar konsep Parsons (1951), setiap sistem sosial diperlukan persyaratan fungsional. Di antara persyaratan itu dijelaskan bahwa sistem sosial harus dapat menyesuaikan diri dengan lingkungan dan dengan tuntutan transformasi pada setiap kondisi tindakan warga (adaptation). Berikutnya, tindakan warga diarahkan untuk mencapai tujuan bersama (goal attainment). Kemudian persyaratan lain adalah bahwa dalam interaksi antarwarga setidaknya harus ada suatu tingkat solidaritas, agar struktur dan sistem sosial berfungsi (integration). Berbicara tentang fungsi ternyata tidak hanya sekedar berkait dengan hal peran. Relasi fungsi tidak selalu terpadu (integratif) karena dapat saja relasi yang saling konflik, lebih-lebih kalau di dalamnya ada cukup banyak fraksi. 


\section{Islam dan Kesejahteraan Masyarakat : Siasat Usaha Pedagang Kaki Lima dengan Pemanfaatan Hubungan Komunitas Muslim}

bentuk yang tidak berdiri sendiri namun memanfaatkan sisi lain dari sistem eknomi kultural9.

Proses pembentukan komunitas dalam masyarakat yang bermula dari pemanfaatan ruang fungsi dan sistem yang hidup di lingkungan masyarakat itu sendiri. Suatu sistem sosial merupakan sistem daripada tindakan-tindakan yang terbentuk dari interaksi sosial. Sistem sosial tersebut terjadi di antara berbagai individu yang tumbuh dan berkembang di atas penilaian umum yang disepakai bersama oleh masyarakat. Kuncinya terletak pada isi penilaian umum tersebut yakni norma, nilai, pengetahuan, simbol sebagai pembentuk komunitas. Sementara pola hubungan komunitas sesama PKL di pasar Suak Bato yang berwujud pada bentukbentuk dari siasat usaha akan dilihat dari munculnya pola-pola pemanfaatan hubungan komunitas dan semangat keislaman akan dilihat dari pendekatan Niklas Luchmann ${ }^{10}$, yakni setiap hubungan yang membentuk komunitas selalu terikutkan didalamnya dimensi moral, dimensi material (budaya) dan dimensi simbol (norma dan nilai). Dalam siasat usaha, semangat keislaman akan terlihat pada dua aspek utama yakni norma dan nilai yang dijalani oleh yang di jalankan oleh PKL. Norma Sosial terbentuk didalam sekumpulan aturan yang diharapkan dipatuhi dan diikuti oleh komunitas PKL pada umumnya tidak tertulis. Sementara nilai-nilai sosial

\footnotetext{
${ }^{9}$ Brown, A. R. Radcliffe, Struktur dan Fungsi dalam masyarakat Primitif. Kuala Lumpur: Dewan Bahasa dan Pustaka, 1980

${ }^{10}$ Nicklas,Luhmann, Social Systems, California: Stanford University Press, 1995, hlm: 80 


\section{Mohammad Syawaludin}

tercerminkan dalam aturan aturan bertindak masyarakatnya ( the rules of conduct) dan aturan-aturan bertingkah laku ( the rules of behavior)

\section{REFERENSI BENTUK SIASAT USAHA}

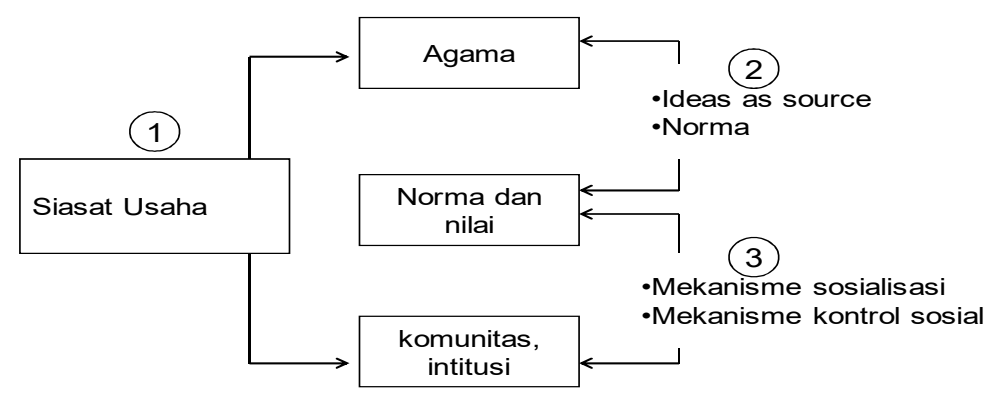

- Nilai, norma, knowledge, simbol, ide disosialisasikan terus menerus sehingga membentuk kepribadian (orientasi, motivasi, kebutuhan)

- Nilai, norma, knowledge, simbol, ide menjadi dasar hubungan sosial, bisa dikoreksi ketika menimbulkan ketegangan (hubungan yang tidak harmonis).

Sumber: Nicklas Luhmann ${ }^{11}$

Ketiga dimensi yang ada dalam hubungan komunitas tersebut akan dilihat nilai-nilai kemanfaatannya dan praksis. Dengan demikian gambaran proses dan pola hubungan di antara ketiga dimensi secara cepat dan mudah dapat dipahami Dengan pendekatan teori fungsionalisme dari Parsons dan Luhmann, fenomena kemampuan bertahan dan mencari cara untuk bisa meningkatkan tarap hidup pedagang kaki lima (PKL) di pasar Suak Bato Palembang dari perspektif sosiologis bisa dideskripsikan secara holistik. Sebab, teori Parsons dan Niklas Luhkmann, akan melihat suatu tindakan kolektif yang dilakukan oleh PKL dengan cara siasat usaha dan

\footnotetext{
${ }^{11}$ Luhmann, 1995, hlm: 145
} 


\section{Islam dan Kesejahteraan Masyarakat : Siasat Usaha Pedagang Kaki Lima dengan Pemanfaatan Hubungan Komunitas Muslim}

menggambarkan suatu realitas yang dinamis dan inovatif. Selain itu, peneliti berpendapat teori fungsionalimse dari Parsons dan Niklas Luhkmann diperlukan ketika memberi penjelasan tentang bagaimana akumulasi dari bentuk-bentuk dari hubungan komunal dan semangat keyakinan terjadi dan dimaknai sebagai suatu bentuk siasat usaha untuk bertahan hidup.

\section{Literatur review}

Ada beberapa hasil penelitian terdahulu yang juga memberi pengaruh terhadap penelitian ini, diantaranya adalah: Penelitian Paiman Raharjo ${ }^{12}$ dapat disimpulkan bahwa PKL perlu ditertibkan dengan mengacu pada landasan hukum dan kebijakan yang tegas dan humanis. Walaupun demikian, perlu diperhatikan juga hak-hak kehidupan dan kesejahterahaan bagi PKL. Raharjo dalam penelitian tersebut lebih fokus pada administrasi dan kebijakan publik, maka tidak mengherankan pendekatan yang digunakan lebih dominan kajian administrasi, managemen dan kebijakan. Raharjo tidak sama sekali menyinggung aspek ideologis maupun moral dari PKL Penelitian Agus Susilo ${ }^{13}$ menunjukan bahwa ada beberapa faktor yang menyebabkan PKL nekat berjualan di bahu jalan salah satunya adalah faktor keterdesakan ekonomi dan safety net.

\footnotetext{
12 Paiman Raharjo, Efektifitas Penertiban Pedagang Kaki Lima di Kecamatan Grogol Jakarta Barat, PPS Universitas Mostopo (Beragama), 2016.

${ }^{13}$ Agus Susilo, Faktor-Faktor yang mempengaruhi Pedagang Kaki Lima Menempati Bahu Jalan Di Kota Bogor Studi Kasus Padagang Sembako Di Jalan Dewi Sartika Utara, PPS UI, 2011
} 


\section{Mohammad Syawaludin}

Penelitian Bambang Rustanto ${ }^{14}$ dapat disimpulkan bahwa pola-pola solidaritas sosial di kalangan PKL di Kota Payakumbuh menunjukan semangat komunitas yang kuat dan saling membantu. Wujud solidaritas sosial salah-satunya adalah tanggungjawab komunitas sesama PKL dan hubungan-hubungan pribadi antar PKL. Bambang melakukan penelitian dengan pendekatan antropologi sosial dengan metode fhenomenologi. Penelitian Umi Mahmudah ${ }^{15}$, menjelaskan bahwa etos kerja pedagang kaki lima perempuan di pasar Induk Bajarnegara adalah aktivitas dinamis yang mempunyai tujuan untuk memenuhi kebutuhan tertentu (jasmani dan rohani) dan dalam mencapai tujuan tersebut dia berupaya dengan penuh kesungguhan untuk mewujudkan prestasi yang optimal sebagai bukti pengabdian dirinya kepada Allah SWT. Adapun etos kerja mereka tercermin dari sikap kerja keras, hemat, jujur, memperkaya jaringan silaturrahim dan tanggungjawab. Sedangkan dalam perspektif ekonomi Islam. Penelitian ini tidak memperhatikan aspek nilai dan norma yang dijadikan dasar membangun kepercayaan. Hasil penelitian Harun dan Atikah Umi Markhamah Zahra Ayyusufi ${ }^{16}$, menjelaskan bahwa belum ada penurunan yang signifikan terhadap PKL Muslim yang berdagang rokok, secara umum belum memiliki dampak ekonomi yang nyata.. Dari berbagai hasil penelitian diatas, secara

\footnotetext{
${ }^{14}$ Bambang Rustanto, Solidaritas Sosial Pedangang KakiLima di Kota Payakumbuh Sumatera Barat, Fisip Andalas 2010

${ }^{15}$ Umi Mahmudah, Etos Kerja Pedagang Perempuan Perspektif Ekonomi Islam (Studi Kasus di Pasar Induk Banjarnegara) Ekonomi Syariah Fakultas Ekonomi dan Bisnis Islam Institut Agama Islam Negeri (IAIN) Purwokerto. 2016

16 Harun dan Atikah Umi Markhamah Zahra Ayyusufi, Dampak Ekonomi Fatwa Mui Tentang Haram Merokok Terhadap Pedagang Kaki Lima (Studi Kasus Di Sepanjang Jl. Slamet Riyadi Surakarta), dalam jurnal SUHUF, Vol. 22, No. 2, Nopember, 2010
} 


\section{Islam dan Kesejahteraan Masyarakat : Siasat Usaha Pedagang Kaki Lima dengan Pemanfaatan Hubungan Komunitas Muslim}

umum saling berkaitan terutama pokok pemikiran penelitian yakni PKL dan pesoalan mata pencarian dan kesejateraan hidup.

Akan tetapi ada dua penelitian yang secara khusus melihat hubungan PKL dengan Islam yakni penelitian Harun dan penelitian Umi Mahmudah. Kedua penelitian ini mencoba menjelaskan PKL dari sisi komunitas muslim yakni etos kerja dan dampak suatu kebijakan terhadap nilai tambah produktifitas PKL muslim. Sementara penelitian Bambang Rustanto tentang solidaritas sosial di Payakumbuh cukup banyak mempengaruhi penelitian ini, terutama dari sisi solidaritas sosialnya, namun dari sisi komunitas tentu berbeda, penelitian Bambang hanya melihat komunitas PKL secara umum. Penelitian siasat usaha pedagang kaki lima di pasar Suak Bato Palembang akan secara khusus akan menjelaskan dan menggambarkan siasat usaha Pedagang Kaki Lima (PKL) sebagai suatu model yang memanfaatkan hubungan komunitas sesama Muslim, bentuk hubungan sosial dan moral tertentu sebagai model pengentasan kemiskinan dari perspektif sosiologis.

\section{Pembahasan}

Seturut dengan latar belakang masalah penelitian ini, maka masalah yang akan diteliti oleh peneliti pada bagian ini adalah pola hubungan dan bentuk pemanfaatan komunitas PKL Muslim di Pasar Suak Bato Palembang. Berdasarkan kajian dan temuan penelitian, maka didapatkan beberapa pola hubungan komunitas PKL Muslim di pasar Suak Bato Palembang . 


\section{Mohammad Syawaludin}

Pola yang berdasarkan pembentukan modal usaha. Modal merupakan salah satu faktor utama bagi PKL untuk membuka usaha dagang mereka baik itu modal sendiri ataupun modal bantuan dari pemertintah untuk membuka usaha. Semakin tinggi modal semakin banyak pula jenis-jenis barang yang akan dijual. Berdasarkan hasil pengamatan langsung di lapangan yang penulis lakukan, pembentukan modal yang dilakukan oleh sebagian PKL menggunakan modal sendiri untuk memulai usahanya perdagangannya walaupun dengan jumlah yang tidak cukup besar dan berharap dengan keuntungan yang sangat besar.

Pola pembagian jenis dagangan dan lapak atau warung tenda dagangan. Model ini merupakan salah satu cara PKL menjaga pola kesetaraan dan solidaritas, sebab lahan atau lapak adalah mata pencaharian utama bagi PKL untuk memenuhi kebutuhan usahanya. Adapun pola pembagian jenis dagangan di antara mereka dilakukan untuk menjaga dan memelihara agar tidak semua jenis komuditas yang mereka jual di setiap pedagang hanya beberapa jenis saja yang mereka dagangkan.

Hasil wawancara dengan beberapa PKL di pasar Suak Bato didapat penjelasan bahwa pembagian jenis dagangan yang di lakukan oleh PKL tersebut tidak hanya terpaku oleh satu distributor saja tetapi disetiap pedagang memiliki distributor atau kulakan lainnya juga. Agar terjadi kesimbangan harga dan sebaran bahan dagangan di pasar. Dinas Pasar tersebut tidak ambil alih mengenai pembagian jenis dagangan yang akan pedagang jual. 


\section{Islam dan Kesejahteraan Masyarakat : Siasat Usaha Pedagang Kaki Lima dengan Pemanfaatan Hubungan Komunitas Muslim}

Hasil penelitian ini menemukan bahwa pola hubungan PKL di pasar Suak Bato Palembang ditentukan oleh dua factor utama yakni:

\section{Jaringan Usaha PKL}

Diteliti gambaran pola jaringan sosial yang ada diantara pedagang kaki lima (PKL), arus penyebaran informasi dalam pola jaringan sosial tersebut, peranperan dalam jaringan komunikasi diantara pedagang kaki lima, dan informasiinformasi yang terdapat dalam jaringan komunikasi tersebut. Hasil penelitian menunjukkan bahwa pedagang kaki lima tersebut membentuk jaringanjaringan atas dasar ikatan persaudaraan, letak/lokasi berdagang dan perasaan senasib sepenanggungan. Sebagai PKL mereka mampu meningkatkan penghasilan diatas rata-rata biaya layak hidup. Intensitas kerja PKL relatif tinggi antara 8-12 jam per hari.

Disamping itu disimpulkan bahwa jaringan komunikasi yang ada terdiri dari simpul dimana antara satu klik dengan yang lain terdapat interaksi yang melibatkan liaisson, bridge, leader, dan isolat. Hubungan antara anggota dalam satu klik berlangsung searah atau dua arah, tergantung dasar pembentukan klik. Interaksi diantara pedagang kaki lima saling bentukan informasi tentang dagangan, permodalan dan keterlibatan umum. Disarankan supaya di sudut-sudut pusat pembelanjaan atau keramaian diadakan suatu kebijaksanaan dalam menata kota, agar terjadi keseimbangan antara pedagang kaki lima dan sektor formal. Perlu adanya penghubung antara pedagang kaki 


\section{Mohammad Syawaludin}

lima dengan pihak pemerintah setempat sehingga ada komunikasi yang baik antara kedua belah pihak. Perlu ada pengarahan kepada pedagang kaki lima oleh pemerintah daerah setempat tentang ketertiban usaha di perkotaan. Dari hasil penelusuran data lapangan ditemukan beberapa bentuk jejaringan PKL yang berlokasi di pasar Suak Bato Palembang diantaranya;
a. Jaringan Asal Lokasi PKL
b. Jaringan Barang yang di Dagangkan
c. Jaringan Sesama Pendatang
d. Jaringan Lokasi atau Zonasi PKL
e. Jaringan Keluarga di antara PKl dan Pemilik lahan.

\section{Pola Tempat Dagang PKL}

Pedagang Kaki Lima (PKL) merupakan kegiatan usaha perdagangan dan jasa untuk dijual di tempat umum baik perorangan maupun kelompok, biasanya bertempat di pinggir jalan ataupun trotoar. Keterbatasan kemampuan modal usaha yang kecil, sehingga dalam menjalankan usahanya menggunakan peralatan yang sederhana. Aktivitas Pedagang Kaki Lima (PKL) memiliki jenis pola perdagangan, antara lain:

a. Pola perdagangan secara mengelompok : berdasarkan pola perdagangan ini, pada umumnya Pedagang Kaki Lima (PKL) memanfaatkan pusat-pusat perbelanjaan untuk menarik Selain itu Pedagang Kaki Lima (PKL) juga biasa menempati ruang-ruang 
Islam dan Kesejahteraan Masyarakat : Siasat Usaha Pedagang Kaki Lima dengan Pemanfaatan Hubungan Komunitas Muslim

terbuka, ujung jalan, sekeliling area pasar, area parkir, serta area taman. Pola perdagangan seperti ini terjadi karena dipengaruhi adanya pertimbangan aglomerasi, yaitu suatu pemusatan atau pengelompokkan pedagang sejenis atau pedagang yang mempunyai sifat komoditas jual yang sama atau saling menunjang, misalnya para pedagang makanan dan minuman.

b. Pola perdagangan secara memanjang : menurut pola perdagangan ini, pada umumnya Pedagang Kaki Lima (PKL) berada di sepanjang jalan, di pinggir jalan utama atau pada jalan yang menghubungkan jalan utama. Dengan kata lain pola perdagangan ini ditentukan oleh pola jaringan jalan itu sendiri. Terjadinya pola perdagangan secara memanjang ini dipengaruhi oleh pertimbangan aksesibilitas yang tinggi pada lokasi yang bersangkutan. Jika dilihat dari sisi Pedagang Kaki Lima (PKL) itu sendiri, pola perdagangan ini sangat menguntungkan. Hal ini disebabkan karena dengan menempatinya lokasi yang beraksesibilitas tinggi maka Pedagang Kaki Lima (PKL) juga akan mempunyai kesempatan yang tinggi dalam menarik konsumen. Jenis perdagangan yang biasa dijual pada pola perdagangan ini adalah buah-buahan, pakaian, kelontong, jasa reparasi. 


\section{Mohammad Syawaludin}

Penelitian ini menemukan bahwa hubungan ajaran Islam dengan kesejateraan PKL Muslim ternyata dapat menjelaskan atau digunakan untuk menjelaskan semangat kerja atau etos kerja para pedagang kaki lima cukup baik, mereka memiliki pandangan yang positif tentang bekerja, bekerja dengan giat, ikhlas tanpa berpangku tangan adalah wujud tanggung jawab mereka terhadap keluarga. ciri etos kerja yang pedagang miliki yaitu menjaga kebersihan, disiplin, sabar dan telaten, hemat dan kerja keras. Etos kerja yang dimiliki para pedagang kali lima salah satunya dimotivasi oleh ajaran agama yang mendorong para pedagang untuk bekerja dan berusaha dengan cara yang halal. Dalam agama juga mewajibkan umatnya untuk bekerja keras agar apa yang mereka inginkan mampu mereka capai. faktor agama, yaitu Islam menganggap bahwa bekerja itu adalah ibadah, dengan kata lain faktor yang memotivasi bekerja adalah hal tersebut.

Islam sangat menekankan kepada pemeluknya agar bersungguh sungguh dalam bekerja, karena bekerja merupakan pekerjaan yang menghasilkan dua hasil sekaligus, yaitu pendapatan dan pahala. Dari seluruh responden yang peneliti jadikan sebagai simpel, semuanya termotivasi tuntutan ekonomi, menafkahi keluarga dan kebutuhan sehari hari. Dalam Islam hal tersebut sudah sebagian dari anggapan bahwa bekerja itu adalah ibadah, namun seluruh responden terhenti hanya sampai disitu. Tidak adanya implementasi dengan perbuatan ibadah langsung membuat anggapan tersebut tidak sempurna (kurang). Hal tersebut terbukti dari hasil 


\section{Islam dan Kesejahteraan Masyarakat : Siasat Usaha Pedagang Kaki Lima dengan Pemanfaatan Hubungan Komunitas Muslim}

observasi, setiap responden melupakan kewajiban mereka sebagai seorang muslim yaitu sholat lima waktu.

Islam mewajibkan setiap muslim untuk bekerja karena itu, salah satu dari ragam bekerja adalah berbisnis. Untuk memungkinkan manusia berusaha mencari nafkah, Allah SWT melapangkan bumi serta menyediakan berbagai fasilitas yang dapat dimanfaatkan manusia untuk mencari rizki Islam menjadi perilaku yang melekat didalam keseharian PKL di pasar Suak Bato, hal ini dapat dipahami dengan melihat kerangka berpikir bahwa ajaran Islam bisa menjadi bagian sumber dari system social, budaya dan personal dari masyarakat. Sebagaimana proses yang terjadi dalam mekanisme fungsional budaya, dimana budaya yakni perilaku keseharian yang bersifat avenus selalu mendatangkan kebaikan, kesejateraan, pembimbingan serta mampu meletakan perilaku keutamaan secara kultural. Sebagimana bingkai proses di bawah ini: 


\section{Mohammad Syawaludin}

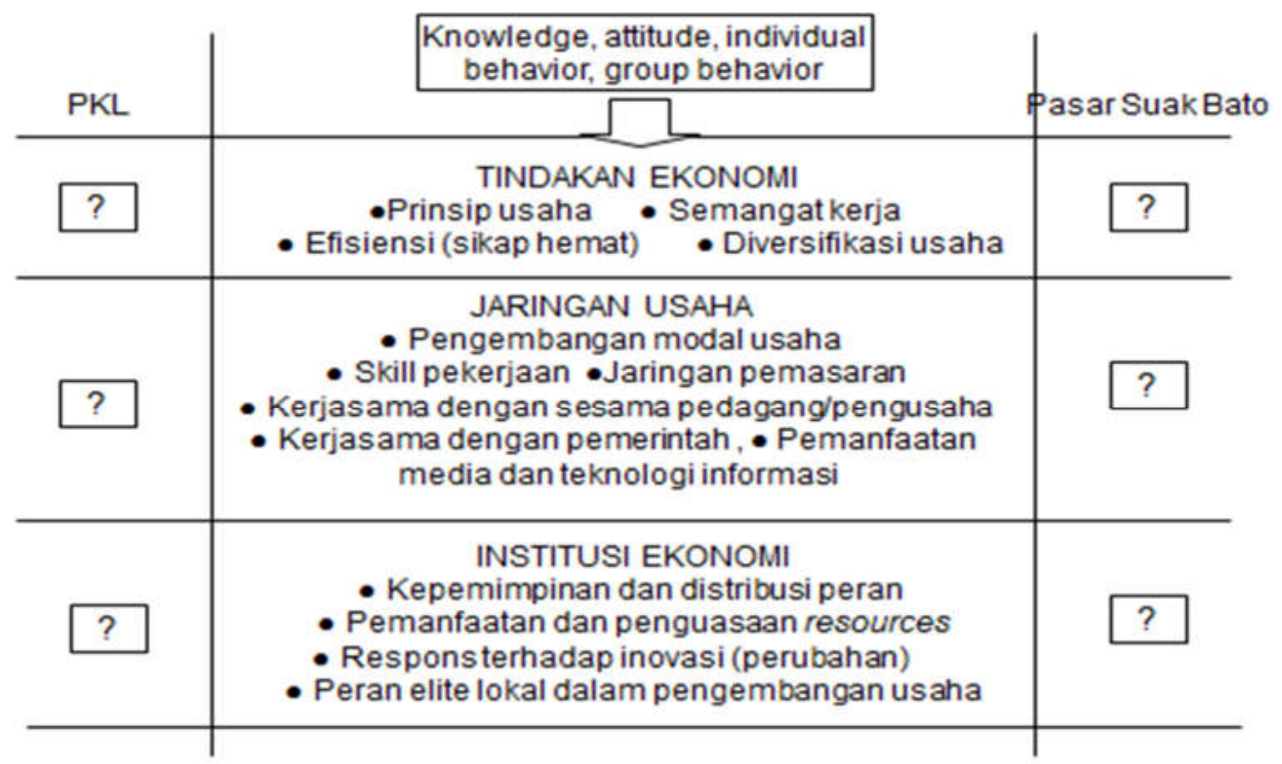

Sumber: data olahan 2017

Gambar di atas memberi penjelasan bahwa ajaran islam yang menjadi perilaku sehari-hari PKL di Pasar Suak Bato Palembang bisa berproses secara kultural, social dan personal di dalam struktur PKL di pasar Suak Bato. Lebih jaur ajaran Islam menjadi perilaku keseharian para PKL meskipun dalam bentuk pengamalan yang terbatas dan tertentu saja. Seperti: sedakah, menjaga kebersihan rumah ibadah, takziah kematian, menjaga kebersamaan, dan jujur dalam timbangan. Ada juga terbuka atas kondisi barang dagangan yang di jual-belikan. Dalam konteks etos Islam dan PKL maka, kewajiban-kewajiban seorang muslim dalam melakukan pekerjaan adalah sebagai berikut:

1. Mengetahui hal-hal yang diperlukan dan dibutuhkan oleh pekerjaan Menyiapkan segala sesuatu yang diperlukan dalam menjalankan pekerjaan agar dapat dengan maksimal mencari rezeki adalah hal yang 


\section{Islam dan Kesejahteraan Masyarakat : Siasat Usaha Pedagang Kaki Lima}

dengan Pemanfaatan Hubungan Komunitas Muslim

dilakukan oleh para pedagang kaki lima. Berusaha semaksimal mungkin merupakan sebuah acuan untuk menjadi lebih baik. Berdasarkan hasil analisa yang dilakukan oleh penulis bahwa semua responden mengetahui hal-hal yang dibutuhkan oleh pekerjaannya.

2. Ikhlas adalah selalu berusaha menghidupkan lentera Ilahi didalam dada dengan niat karena Allah SWT, dan berserah diri kepadaNya serta selalu mensyukuri nikmat yang telah diberikan Allah SWT. Ikhlas dalam suatu menjalankan pekerjaan maksudnya yaitu dengan di tandai semangat juang yang tinggi dan tidak pernah menunggalkan Allah dalam setiap pekerjaannya. Bedasarkan analisis data yang didapat dari responden menunjukan bahwa semua responden meyakini kalau bekerja itu harus selalu mengingat Allah SWT. dan mensyukuri apa yang telah diberikanNya.

3. Menunaikan janji di antara hak pekerjaan Janji merupakan hal yang harus ditunaikan, "al wa' du dainun" yang artinya janji adalah hutang dan salah satu hak seorang muslim kepada muslim lainnya adalah menepati janji.

4. Pekerjaan yang halal, di dalam Islam tidak ada perbedaan dalam pekerjaan yang paling baik atau tidak, dimata Allah SWT. Semua pekerjaan adalah baik sepanjang tidak bertentangan dalam syariat Islam itu sendiri. Pekerjaan yang paling baik adalah pekerjaan yang halal. Selain itu Islam juga tidak pernah memberikan batasan kepada umatnya 


\section{Mohammad Syawaludin}

untuk berusaha dan mendapatkan usaha yang baik dan dikehendakinya. Kemudian Islam juga memberikan kebebasan yang seluas-luasnya dalam perlombaan mencari usaha yang halal dan direstui Allah SWT.

Pada diri PKL muslim yang berjualan di pasar Suak Bato selalu menunjukan perilaku keislaman dalam bentuk pengetahuan, attitude, perilaku keseharian, dan solidaritas social yang baik dan unggul. Meskipun perilaku keseharian itu tidak merata di kalangan PKL Muslim Pasar Suak Bato Palembang, paling tidak perilaku keseharian Islami tersebut bisa menajdi attitude teladan bagi PKL lainnya. Seperti perilaku menghormati pedagang lain, sedekah untuk kebersihan tempat ibadah, membedakan dagangan yang BS dan Baik, takaran timbangan yang sesuai, tidak berbuat seenaknya sendiri atau perbuatan lainnya.

Dalam penelitian ini menemukan kenyataan bahwa ajaran Islam yang praktekan sehari-hari oleh para PKL tersebut merupakan bagian yang mereka peroleh dari berbagai macam jalur pembelajaran secara alamiah saja. Ini yang menjadikan praktek ajaran Islam keseharian di kalangan PKL tidak meratakan bahkan terkesan apa adanya saja. Namun ada juga para PKL tersebut memang berasal dari kultur keluarga yang mendalami ajara Islam secara baik dan benar. Temuan ini mempertegas bahwa lingkungan pergaulan dan bentuk aktifitas para PKL sangat memberikan pengaruh besar bagi terwujudnya nilai-nilai ajaran islam keseharian di kalangan PKL itu sendiri. Ajaran-ajaran islam keseharian yang dilakukan oleh PKL pasar Suak Bato merupakan ajaran Islam yang mudah dan 


\section{Islam dan Kesejahteraan Masyarakat : Siasat Usaha Pedagang Kaki Lima}

dengan Pemanfaatan Hubungan Komunitas Muslim

parktis saja. Seperti; shalat, infaq, takziyah, bersuci. jujur, ramah, saling percaya dan menjaga, toleransi. Dari hasil penelitain ditemukan ada beberapa cara atau metode para PKL tahu akan ajaran Islam keseharian di antaranya:

\begin{tabular}{|c|c|c|}
\hline & \multicolumn{2}{|c|}{ CARA TAHU AJARAN ISLAM KESEHARIAN } \\
\hline NO & $\begin{array}{c}\text { CARA/METODE TAHU } \\
\text { AJARAN ISLAM }\end{array}$ & INTITUSI \\
\hline 1 & $\begin{array}{l}\text { Lingkungan dan } \\
\text { keluarga Muslim }\end{array}$ & $\begin{array}{l}\text { Teman. Keluarga, sesame } \\
\text { pedagang yang memiliki } \\
\text { pengetahuan islam lebih baik } \\
\text { dan mudah dipahami }\end{array}$ \\
\hline 2 & $\begin{array}{l}\text { Belajar secara tidak } \\
\text { formal }\end{array}$ & $\begin{array}{l}\text { Pengajian, perkumpulan dan } \\
\text { guru mengaji }\end{array}$ \\
\hline 3 & $\begin{array}{l}\text { Belajar dan melalui } \\
\text { pendidikan formal }\end{array}$ & $\begin{array}{l}\text { Pesantren, madrasah dan } \\
\text { pengajian formal lainnya }\end{array}$ \\
\hline 4 & $\begin{array}{l}\text { Membaca, mendengar, } \\
\text { diberitahu dan lainnya }\end{array}$ & $\begin{array}{l}\text { Perorangan, kelompok } \\
\text { pengajian, jamaah dan } \\
\text { masjid. }\end{array}$ \\
\hline
\end{tabular}

Sumber: Data Olahan penelitian 2017

Tabel diatas menjelaskan bahwa pada umumnya PKL di pasar Suak Batok tahu Islam dan ajaran Islam karena keluarganya beragama Islam dan belajar Islam dari guru ngaji atau mendengar ceramah atau tauziyah. Namun ada juga sebagian PKl memang mempelajari ajaran Islam melalui pendidikan seperti pesantren atau aliyah.

Pada umumnya perilaku PKL Muslim di pasar Suak Bato selalu menunjukan perilaku keseharian yang tentunya tidak berbedaa dengan perilaku sehari-hari pedagang sebagaimana biasa. Tidak berlebihan bila pengaruh ajaran Islam di dalam diri PKL Muslim inheren dengan perilaku pada umumnya muslim lainnya. Namun demikian, ajaran Islam sangat memberi pengaruh terhadap cara dan 


\section{Mohammad Syawaludin}

sikap keseharian para PKL Muslim di pasar Suak Bato Palembang. Dapat di lihat dari garis sibernetika perilaku sebagai berikut ini;

SIBERNETIKA KESESUAIAN ANTARA HUBUNGAN KOMUNITAS DENGAN ETOS PKL MUSLIM BERDAMPAK PADA PENINGKATAN KESEJATERAAN

\begin{tabular}{|c|c|c|}
\hline NO & Bentuk Aktivitas & Perilaku Islam \\
\hline 1 & $\begin{array}{l}\text { Mempersiapakan dagangan } \\
\text { sejak jam } 3 \text { Malam }\end{array}$ & $\begin{array}{l}\text { Menjelang Azan Subuh sebagian } \\
\text { PKL melaksanakan sholat subuh } \\
\text { berjamah di masjid yang berada di } \\
\text { pasar } 26 \text { Ilir atau sekitar lokasi. }\end{array}$ \\
\hline 2 & $\begin{array}{l}\text { Mencatat transaksi } \\
\text { dagangan yang di ambil } \\
\text { dari agen }\end{array}$ & $\begin{array}{l}\text { Setiap transaksi jual beli selalu ada } \\
\text { catatan tersendiri agar tidak terjadi } \\
\text { kebohongan atau kealfan }\end{array}$ \\
\hline 3 & $\begin{array}{l}\text { Merapikan atau menyusun } \\
\text { dagangan sesuai dengan } \\
\text { jenis dan bentuknya }\end{array}$ & $\begin{array}{l}\text { Kebersihan dan keindahan adalah } \\
\text { ciri dari orang yang beriman agar } \\
\text { mendapatkan barakah berdampak } \\
\text { pada meningkatnya konsumen }\end{array}$ \\
\hline 4 & $\begin{array}{l}\text { Menyiapkan Barang } \\
\text { Dagangan }\end{array}$ & $\begin{array}{l}\text { Ikut memberi bantuan } \\
\text { menyiapkan barang dagangan } \\
\text { sesama PKL }\end{array}$ \\
\hline 5 & $\begin{array}{l}\text { Melayani konsumen secara } \\
\text { baik dan selalu mengajak } \\
\text { berkomunikasi }\end{array}$ & $\begin{array}{l}\text { Memberi atau menyampaikan } \\
\text { jenis barangan atau kualitas } \\
\text { barang kepada konsumen secara } \\
\text { terbuka. }\end{array}$ \\
\hline 6 & $\begin{array}{l}\text { Memberi dagangan yang } \\
\text { dibeli konsumen dengan } \\
\text { takaran yang tepat }\end{array}$ & $\begin{array}{l}\text { Bila timbangan pedagang } \\
\text { meragukan, biasanya PKL tersebut } \\
\text { meminjam timbangan PKL } \\
\text { lainnya, untuk mencocokan } \\
\text { timbangannya. }\end{array}$ \\
\hline 7 & $\begin{array}{l}\text { Selalu menjaga hubungan } \\
\text { baik dengan sesama PKL } \\
\text { agar pembeli nyaman dan } \\
\text { seterusnya. }\end{array}$ & $\begin{array}{l}\text { Berkomunikasi dengan cara } \\
\text { bercanda dan sejenisnya, bahkan } \\
\text { disisikan dengan nasehat atau } \\
\text { hikmah. }\end{array}$ \\
\hline
\end{tabular}

Sumber: hasil olah data lapangan 2017 


\section{Islam dan Kesejahteraan Masyarakat : Siasat Usaha Pedagang Kaki Lima dengan Pemanfaatan Hubungan Komunitas Muslim}

Table di atas memberi gambaran secara sederhana bagaimana hubungan yang terjadi di antara sesama PKL di pasar Suak Bato. Keterbauran antara pengamalan ajaran Islam dengan perilaku sehari-hari masih nampak sangat diperhatikan dan dijunjung tinggi sebagai sebuah norma dan etika yang bersumber dari ajaran Islam. Hal tersebut ikut membentuk pemanfaatan hubungan komunitas antar PKL menjadi modal sosial dengan berbagai jenis dan fungsionalnya.

Temuan lainnya dalam penelitian ini adalah hubungan pemanfaatan komunitas antar PKL yang berdampak pada peningkatan kesejateraan mereka adanya hidup mengelompok bagi PKL perantau, bukan atas kesengajaan namun cenderung kepada sebuah kebutuhan dan kebetulan, karena mereka memiliki kesamaan kegiatan dan aktivitas. Biasanya mereka berkumpul dalam satu rumah atau lokasi sesama perantau dengan membayar sewa secara urunan sesama mereka. Bagi para PKL pendatang menjaga hubungan baik antar mereka adalah akan mendatangkan manfaat yang berdampak pada kesejateraan. Sebab, ada kenyataan bahwa PKL perantau atau pendatang mengawali berjualan di kaki lima dengan modal kecil, jenis barang yang mereka jual adalah kaos kaki, pakaian dalam dan jam tangan yang harganya relatif murah. Baru kemudian setelah memiliki modal yang cukup mereka mengganti dengan jenis pakaian jadi dewasa dan anak-anak serta pakaian busana muslim. 


\section{Mohammad Syawaludin}

\section{Kesimpulan}

Relevansinya dengan ajaran Islam didalam kehidupan para PKL muslim pasar Suak Bato Palembang berdasarkan hasil temuan lapangan menunjukan wujud praktik yang bervariasi dan terkait juga dengan kesadaran PKL serta lingkungan di sekelilingnya. Namun masih bisa dirasakan bahwa ajaran Islam memepengaruhi perilaku sehari-hari para PKL muslim didalam peniagaan mereka. Narasi Islam yang dipraktekan oleh para PKL muslim diantaranya; perilaku ikhlas, menjaga dagangan tetap halal, perilaku barakah, perilaku jujur dan adil serta terbuka dalam timbangan. Perilaku toleran dan saling membantu baik ketika transaksi maupun ketika display dagangan. Praktek-praktek tersebut mendorong meningkatnya nilai kesejateraan dan capai hidup para PKL. Sebab berpengaruh terhadap sirkulasi dagangan dan konsumen. Padagang Kaki Lima Muslim pasar Suak Bato yang tergabung didalam PKL Muslim menggambarkan suatu sekelompok PKL yang perilakunya berbeda dengan kebanyakan PK1 lainnya. Ada semangat merubah keadaan new entrepreneur, melakukan serangkaian tindakan (human actions). Tindakan itu didasarkan pada semangat kapitalisme (spirit of capitalism). Semangat kapitalisme terdiri dari tiga hal; motif memperoleh laba (profit motive), hidup zuhud dan sederhana (ascetic orientation) semangat misi (ideas of calling). 


\section{Islam dan Kesejahteraan Masyarakat : Siasat Usaha Pedagang Kaki Lima dengan Pemanfaatan Hubungan Komunitas Muslim}

\section{DAFTAR PUSTAKA}

An-nat, B.(1993). Implementasi Kebijakan Penanganan PKL : Studi Kasus di

Yogyakarta dan DKI, Pascasarjana Magister Administrasi Publik. UGM.:

Yogyakarta

Ananta, A, (2000), Ekonomi Sumber Daya Manusia, Jakarta: LPFE UI, Jakarta

Brown, A. R. Radcliffe, 1980, Struktur dan Fungsi dalam masyarakat

Primitif. Dewan Bahasa dan Pustaka: Kuala Lumpur

ath-Thahawi,I. (1973). Al-Iqtishad al-Islami, volume I, Majma' al-Buhuts alIslamiyyah: Kairo

Ali, Y. (1946). The Holy Quran: Translation and Comentary. Islamic Propagation Centre, no 1200: Lahore

Coleman, James S., (1988), "Social Capital in the Creation of Human Capital." American Journal of Sociology Supplement. America

Damsar, (2009), Pengantar Sosiologi Ekonomi. Jakarta: Kencana Prenata Media Group

Hardiman, Francisco, Budi, (1990), Kritik Ideologi-Pertautan Pengetahuan dan

Kepentingan. Penerbit Kanisius, Yogyakarta

Hamilton, P. (2000). Reading From Talcott Parsons. Terjemahan oleh Hartono Hadikusumo, Tiara Wacana, Yogyakarta

Hadjon, P. (2004). Hukum Administrasi Negara. Rineka, Yogyakarta

Homans, George C, (1974), Elementary Forms of Social Behavior, (2nd Ed,.: Harcourt Brace Jovanovich: New York

Ismail Yusanto dkk, (2002), Menggagas Bisnis Islam, Gema Insani Press, cet. 1: Jakarta

Julius, B. ( 2003), Transformasi Ekonomi Rakyat. Jakarta, Pustaka Cidesindo, 


\section{Mohammad Syawaludin}

Mahmudah, U. (2016), Etos Kerja Pedagang Perempuan Perspektif Ekonomi Islam (Studi Kasus di Pasar Induk Banjarnegara) Ekonomi Syariah Fakultas Ekonomi dan Bisnis Islam Institut Agama Islam Negeri (IAIN),Purwokerto.

Mustaq Ahmad, (2001), Etika Bisnis Dalam Islam: Pustaka Al-Kautsar: Jakarta

Manning, Chris dan Tadjuddin Noer Effendi,(1991) Urbanisasi, Pengangguran, dan Sektor Informal di Kota, Jakarta: Yayasan Obor Indonesia.

Mc Adam, Doug, John D. McCarthy and Mayer N. Zald (eds). (1996). Comparative perspection social Movements: Political Opportunities, Mobilizing structure and Cultural Framing, New York: Cambridge University Press.

Mun'im Khallaf, Muhammad, tt, Al-Madiyyah allslamiyyah wa 'Abduhu, Daar alMa'arif : Kairo:

Nahdliyulizza.(2010) Pengaruh Pasar Modern Terhadap Pedagang Pasar Tradisional,, Skripsi Universitas Islam Negeri Sunan Kalijaga, Yogyakarta

Knodt Eva M.(1995). “Foreword”, dalam Niklas Luhmann, Social Systems : Stanford University Press, California

Luhmann Nicklas.(1995). Social Systems, Stanford University Press, California 1987, Archimedes und wir: Interviews, Dirk Baecker dan Georg Stanitzek (ed), Berlin

Raharjo, P.(2016). Efektifitas Penertiban Pedagang Kaki Lima di Kecamatan

Grogol Jakarta Barat, PPS Universitas Mostopo (Beragama) : Jakarta

Rustanto, B.(2010). Solidaritas Sosial Pedangang KakiLima di Kota

Payakumbuh Sumatera Barat, Fisip Andalas: Padang

Ritzer, George and Douglas J. Goodman.(2009).Sociological Theory, 6th Ed.

McGrawHill. Boston

Raji al-Faruqi, Ismail. (1979). Is Islam Defineable in Terms of His Economic Pursuit, dalam buku Islamic Perspectives, editor Khursyid Ahmad dan Zafar Ishaq Anshari, Leicester : Islamic Foundation 


\section{Islam dan Kesejahteraan Masyarakat : Siasat Usaha Pedagang Kaki Lima dengan Pemanfaatan Hubungan Komunitas Muslim}

Purwanti, H dan Misnarti.(2012). Usaha Penertiban dan Pembinaan Pedagang Kaki Lima di Kabupaten Lumajang. Jurnal Sekolah Tinggi Ilmu Hukum (STIH) Jenderal Sudirman Lumajang.

Satriani, Dede Sam.(2011). Prospek Usaha Pedagang Kaki lima Pantai Selat Baru Kecamatan Bantan Kabupaten Bengkalis Menurut Perspektif Ekonomi Islam. Thesis, PPS Universitas Islam Negeri Sultan Syarif Kasim, Riau

Singgih, Doddy S. 1999, "Metode Analisis Fungsi Lahan," Masyarakat Kebudayaan dan Politik, Th XII, No 3, Juli: Jakarta

Scott, James C. (1976). popularized E.P. Thompson's idea with his well-known study of peasant revolts in Vietnam and Burma, The Moral Economy of the Peasant: Rebellion and Subsistence in Southeast Asia New Haven: Yale University Press, America

Schejtman.A. (1984). The peasant economy internal logic; articulation nd persintence dalam the political economy of underdevolepment, C.K.Wilber ed, Raundem House : NewYork

Susilo, A. (2011). Faktor-Faktor yang mempengaruhi Pedagang Kaki Lima Menempati Bahu Jalan Di Kota Bogor Studi Kasus Padagang Sembako Di Jalan Dewi Sartika Utara, PPS UI : Jakarta

Thompson. (2012) Customs in Common, Merlin Press, London

Torrey Charles C, 1892, The Commercial-Theological Terms in the Koran, Leyden: E.j.Brill. Belanda

Waluyo. (2016). Kebijakan daerah dalam penataan Pedagang Kaki lima (PKL) guna mewujudkan pengelolaan PKL yang partisipatif dan berkeadilan di kota Surakarta. Fakultas Hukum Unversitas S George C. Homans, Elementary Forms of Social Behavior, (2nd Ed.), New York: Harcourt Brace Jovanovich, (1974) sebelas Maret, Surakarta

Wirosardjono Soetjipto. (1985) Pengembangan Swadaya Nasional, Tinjauan ke arah persepsi yang utuh, LP3ES: Jakarta 


\section{Mohammad Syawaludin}

Jurnal dan Sumber lainnya

Harun dan Atikah Umi Markhamah Zahra Ayyusufi. (2010) Dampak Ekonomi Fatwa Mui Tentang Haram Merokok Terhadap Pedagang Kaki Lima (Studi Kasus Di Sepanjang Jl. Slamet Riyadi Surakarta), dalam jurnal SUHUF, Vol. 22, No. 2, Nopember. Surakarta

M. Hasyim, definisi-pedagang- kaki-lima dalam http://id.shvoong.com/social_-

sciences/sociology, di akses pada tanggal 26 April 2017.

Maturana, Humberto \& Varela, Francisco, Autopoiesis and Cognition: the Realization of the Living. Robert S. Cohen and Marx W. Wartofsky (Eds.), Boston Studies in the Philosophy of Science, New York, Oxford University Press, Dalam http://en.wikipedia.org/wiki/Autopoiesis, diakses tanggal 26 April 2017

Wikipedia Indonesia, Ensiklopedia Bebas Berbahasa Indonesia, di akses 26 April 2017 